\title{
Factors associated with gustatory threshold for salty taste in peritoneal dialysis patients
}

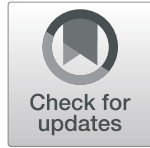

Kenta Torigoe ${ }^{1}$, Yoko Obata ${ }^{1,2^{*}}$, Shimpei Morimoto ${ }^{3}$, Miki Torigoe $^{1}$, Satoru Oka ${ }^{1}$, Tadashi Uramatsu', Hiroshi Mukae ${ }^{4}$ and Tomoya Nishino ${ }^{1}$

\begin{abstract}
Background: Taste disorder is a common problem in patients with chronic kidney disease and end-stage renal disease. Specifically, salty taste disorder is associated with excess salt intake. Many factors affect taste activity; however, data focused on peritoneal dialysis (PD) patients are limited. This study aimed to investigate the distribution of the gustatory threshold for salty taste and to clarify its relevant contributing factors in PD patients.

Methods: In this retrospective cross-sectional study, we enrolled 22 PD patients who were assessed for their detection and recognition thresholds for salty taste using salt-impregnated test strips. We investigated the distribution of the detection and recognition thresholds and analyzed their relevant factors.

Results: In PD patients, detection and recognition threshold for salty taste were both high. Especially, most of the PD patients could not recognize salty taste even at the highest concentration level. The high detection threshold was associated with young age, long duration of PD, high serum phosphorus, and high transferrin saturation. The high recognition threshold was associated with long duration of PD, high serum phosphorus, high creatinine, high serum $\beta_{2}$ microglobulin, low renal $\mathrm{Kt} / \mathrm{N}$, and high peritoneal $\mathrm{Kt} / \mathrm{N}$. Partition analysis showed that high serum phosphorus was related with high detection threshold and low renal Kt $N$ was related with high recognition threshold.

Conclusions: This study demonstrated that the gustatory threshold for salty taste was increased in PD patients. In addition, high detection threshold was related with high serum phosphorus and high recognition threshold was related to low renal $\mathrm{Kt} / \mathrm{N}$. Based on these findings, we consider that it is important to assess the gustatory threshold for salty taste in PD patients, particularly those with high serum $\mathrm{P}$ and low renal $\mathrm{Kt} / \mathrm{N}$.
\end{abstract}

Keywords: Chronic kidney disease, End-stage renal disease, Excess salt intake, Salty taste disorder, Taste disorder

\section{Background}

Salt is essential for maintaining homeostasis. However, excess salt intake is associated with various adverse events including hypertension, stroke, cardiovascular disease, and all-cause mortality $[1,2]$. Specifically, most chronic kidney disease (CKD) and end-stage renal disease (ESRD) patients are sensitive to salt, and excess salt intake accelerates kidney disease progression in these patients [3-5]. Thus, dietary salt restriction is recommended to prevent the

\footnotetext{
* Correspondence: yobata-ngs@umin.ac.jp

'Department of Nephrology, Nagasaki University Graduate School of Biomedical Sciences, 1-7-1 Sakamoto, Nagasaki 852-8501, Japan

${ }^{2}$ Medical Educational Development Center, Nagasaki University Hospital, 1-7-1 Sakamoto, Nagasaki 852-8501, Japan

Full list of author information is available at the end of the article
}

deterioration of renal function in CKD and ESRD patients [6-8]. However, adherence to a salt-restricted diet is not frequently achieved despite these recommendations [9]. Nonadherence to salt restriction appears to be a complex problem because previous studies showed that patients face multiple barriers when salt intake is restricted, including (i) reduced palatability of low-salt foods, (ii) inconvenience or difficulty in preparing a low-salt diet, and (iii) lack of knowledge or understanding of the benefit and practice of a low-salt diet [10]. In addition to these factors, taste disorder is known to be associated with the amount of dietary salt intake $[11,12]$.

Taste disorder including salty taste disorder is a common problem in CKD and ESRD patients [13, 14]. It is not certain what induces taste disorder in CKD and 
ESRD patients; however, many factors are thought to affect taste activity in this patient population. Previous studies showed that zinc deficiency and uremia led to taste disorder, and zinc supplement and implementation of hemodialysis (HD) improved taste activity [15, 16]. Moreover, excess salt intake itself was reported to increase the gustatory threshold for salty taste, and salty taste disorder was improved by salt restriction in CKD patients [17-19]. Furthermore, decreasing taste buds and increasing salivary urea associated with azotemia are related to taste disorder in CKD and ESRD patients $[20,21]$. Some causes of salt taste disorder in these patients are modifiable; for this reason, diagnosis and treatment for salty taste disorder might be effective strategies to achieve salt restriction.

Peritoneal dialysis (PD) is one of the renal replacement therapies for ESRD, and it has been reported that salty taste activity is decreased in PD patients [22]. However, little is known about the relationship between clinical factors and the gustatory threshold for salty taste in PD patients since previous studies are mainly focused on CKD or HD patients. Therefore, in this study, we investigated the distribution of gustatory threshold for salty taste and aimed to clarify its relevant factors in PD patients.

\section{Methods}

\section{Patient selection}

We perform nutritional guidance for PD patients at least once a year at our hospital, and as part of this usual guidance, we assessed the recognition threshold for salty taste using salt-impregnated test strips since 2015. In this retrospective, cross-sectional study, we enrolled 22 PD patients who were assessed for their gustatory threshold for salty taste with nutritional guidance in a university hospital between October 2015 and January 2017. All patients had never been diagnosed with taste disorder. We excluded patients who received a combination therapy with both PD and HD, had active infection, or could not respond to the kind of taste they recognized (e.g., dementia).

\section{Data collection}

We collected clinical data from medical records at the first time of taste assessment and at the time of the first peritoneal equilibration test during the study period. Peritoneal equilibration test and measurement of daily salt excretion were carried out while patients were hospitalized. Results of these examinations were also collected (within 1 year from taste assessment). Daily salt excretion, which represents daily salt intake, was calculated as daily urinary salt excretion plus daily peritoneal salt removal.

\section{Assessment of gustatory threshold for salty taste}

For the assessment of gustatory threshold for salty taste, a salt-impregnated taste strip Salsave (Advantec Tokyo Co. Ltd, Tokyo Japan), which is impregnated with various salt concentrations $(0.6,0.8,1.0,1.2,1.4$, and 1.6 $\mathrm{mg} / \mathrm{cm}^{2}$; normal range, 0.6 to $0.8 \mathrm{mg} / \mathrm{cm}^{2}$ ), was used [23, 24]. Salsave has been validated using the whole-mouth method as a standard [23]. Assessment was performed according to the manufacturer's instruction. Briefly, the subjects were first asked to rinse their mouths with distilled water to neutralize oral conditions as much as possible. They were then asked to place a strip saturated with $0 \mathrm{mg} / \mathrm{cm}^{2}$ salt chloride on their tongue for $3 \mathrm{~s}$ to familiarize themselves with the taste of a blank strip. Patients were asked to place a strip on their tongue, and the lowest concentration at which patients could detect some kind of taste, but could not recognize the kind of taste, was considered the detection threshold. The lowest concentration at which patients identified the salt taste was taken as the recognition threshold. Patients who could not detect or recognize taste, even at the highest concentration level $\left(1.6 \mathrm{mg} / \mathrm{cm}^{2}\right)$, were assigned a detection or recognition threshold of $1.8 \mathrm{mg} / \mathrm{cm}^{2}$.

\section{Statistical analysis}

To investigate the clinical parameter associated with detection and recognition thresholds, we divided the PD patients into two groups according to the normal value. The normal value of detection threshold was below $0.6 \mathrm{mg} /$ $\mathrm{cm}^{2}$, and recognition threshold was below $0.8 \mathrm{mg} / \mathrm{cm}^{2}$ [25]. Therefore, the detection threshold was divided into the normal $\left(\leqq 0.6 \mathrm{mg} / \mathrm{cm}^{2}, n=7\right)$ and high $\left(\geqq 0.8 \mathrm{mg} / \mathrm{cm}^{2}\right.$, $n=15)$ detection group. Then, the recognition threshold was divided into the normal $\left(\leqq 0.8 \mathrm{mg} / \mathrm{cm}^{2}, n=5\right)$ and high $\left(\geqq 1.0 \mathrm{mg} / \mathrm{cm}^{2}, n=17\right)$ recognition group. The Fisher's exact test was used to test of independence between two nominal variables. The Wilcoxon rank-sum test was used for the test of association between a nominal variable and a continuous one. Statistical hypotheses were tested with the significance level of 0.05 . The clinical factors related to high detection and recognition thresholds were mined using C5.0 (Quinlan JR, RuleQuest.com, last accessed: July 18,2019$)$ that is a cluster entropy-based partitioning method. Because of the small sample size of this study, we did not include boosting within the algorithm. Statistical analyses were performed using JMP version 13 software (SAS Institute Inc., Cary, NC, USA) or R, a language and environment for statistical computing ( $R$ Foundation for Statistical Computing, Vienna, Austria).

\section{Results}

\section{Patient characteristics}

The clinical characteristics of PD patients are shown in Table 1. The median age of patients was $63(55-78)$ 
years, and 10 patients were men (45.5\%). The median PD duration was 26 (6-62) months. The primary causes of ESRD were nephrosclerosis (36.4\%), chronic glomerulonephritis (27.3\%), and diabetic nephropathy (13.6\%). Systolic blood pressure was relatively controlled (133 [122-144] mmHg). Daily salt excretion, which represents daily salt intake, was relatively high (8.0 [6.5-11.2] g/day). Serum zinc was relatively low (62 [55-77] mg/ $\mathrm{dL}$ ). The total $\mathrm{Kt} / \mathrm{V}$ urea (dialytic + residual) was 1.98 (1.79-2.37), which implied that low solute clearance was enough.

\section{Distribution of detection and recognition threshold for salty taste in PD patients}

As shown in Table 1, the median detection and recognition threshold for salty taste were both high $(0.8$ [0.6$1.6] \mathrm{mg} / \mathrm{cm}^{2}$ and $1.8[1.0-1.8] \mathrm{mg} / \mathrm{cm}^{2}$; normal range of detection threshold, $\leqq 0.6 \mathrm{mg} / \mathrm{cm}^{2}$; normal range of recognition threshold, $\leqq 0.8 \mathrm{mg} / \mathrm{cm}^{2}$ ). The distribution of detection and recognition threshold for salty taste is shown in Fig. 1. Fifteen (68\%) patients presented with a detection threshold above $0.8 \mathrm{mg} / \mathrm{cm}^{2}$, and $2(14 \%)$ patients could not detect salty taste, even at the highest concentration level $\left(1.6 \mathrm{mg} / \mathrm{cm}^{2}\right)$. Furthermore, 17 (77\%) patients presented with a recognition threshold above $1.0 \mathrm{mg} / \mathrm{cm}^{2}$, and $12(55 \%)$ patients could not recognize salty taste, even at the highest concentration level.

\section{Clinical parameters associated with detection and recognition threshold for salty taste in PD patients} Clinical parameters associated with gustatory threshold for salty taste in PD patients are shown in Table 2. High detection threshold group was associated with young age, long duration of $\mathrm{PD}$, high serum $\mathrm{P}$, and high TSAT. Furthermore, high recognition group was associated with long duration of $\mathrm{PD}$, high serum $\mathrm{P}$, high serum $C r$, high serum $\beta_{2}$ microglobulin, high peritoneal $\mathrm{Kt} / \mathrm{V}$, and low residual renal $\mathrm{Kt} / \mathrm{V}$. However, with both high detection and high recognition thresholds, the association of neither serum zinc nor daily salt excretion, which were previously reported to be related to taste disorder, was significant.

Table 1 Characteristics of PD patients

\begin{tabular}{|c|c|c|c|}
\hline Age (years) & $63(55-78)$ & $\mathrm{Cl}(\mathrm{mEq} / \mathrm{L})$ & 104 (99-107) \\
\hline Male:female & $10: 12$ & Corrected Ca (mg/dL) & $9.6(9.2-10.2)$ \\
\hline Duration of PD (months) & $26(6-62)$ & $P(\mathrm{mg} / \mathrm{dL})$ & $5.1(3.9-5.6)$ \\
\hline Primary diseases of ESRD (\%) & & $\mathrm{Zn}(\mu \mathrm{g} / \mathrm{dL})$ & $62(55-77)$ \\
\hline Chronic glomerulonephritis & 27.3 & Intact-PTH (pg/mL) & $139(55-215)$ \\
\hline Nephrosclerosis & 36.4 & BUN (mg/dL) & $55(47-61)$ \\
\hline Diabetic kidney diseases & 13.6 & $\mathrm{Cr}(\mathrm{mg} / \mathrm{dL})$ & $7.6(6.1-11.3)$ \\
\hline Other & 22.7 & $\cup A(m g / d L)$ & $6.4(5.4-7.1)$ \\
\hline Comorbidity (\%) & & $\beta_{2}$ microglobulin (mg/L) & $16(12-21)$ \\
\hline Hypertension & 86.4 & Ferritin (ng/mL) & $160(91-283)$ \\
\hline Diabetes mellitus & 22.7 & TSAT (\%) & $34(26-49)$ \\
\hline Cardiovascular diseases & 18.1 & $\mathrm{HCO}_{3}^{-}(\mathrm{mmol} / \mathrm{L})$ & $24(23-28)$ \\
\hline Modality of PD (CAPD:APD) & $12: 10$ & $\mathrm{CRP}(\mathrm{mg} / \mathrm{dL})$ & $0.14(0.04-0.64)$ \\
\hline Body weight (kg) & $60(51-64)$ & Urinary protein (g/g Cr) & $1.1(0.7-3.6)$ \\
\hline Systolic BP (mmHg) & $133(122-144)$ & CTR (\%) & $50(48-59)$ \\
\hline Diastolic BP (mmHg) & $71(59-85)$ & Total Kt/N & $1.98(1.79-2.37)$ \\
\hline Effluent volume (mL/day) & $287(173-695)$ & Peritoneal Kt/N & $1.19(0.82-1.77)$ \\
\hline Urinary volume (mL/day) & $1100(933-1500)$ & Renal Kt/N & $0.86(0.44-1.27)$ \\
\hline $\mathrm{Hb}(\mathrm{g} / \mathrm{dL})$ & $10.8(9.8-11.8)$ & Salt excretion (g/day) & $8.0(6.5-11.2)$ \\
\hline $\mathrm{TP}(\mathrm{g} / \mathrm{dL})$ & $6.6(6.0-6.9)$ & Detection threshold for & $0.8(0.6-1.6)$ \\
\hline Alb $(\mathrm{g} / \mathrm{dL})$ & $3.4(3.1-3.6)$ & salty taste $\left(\mathrm{mg} / \mathrm{cm}^{2}\right)$ & \\
\hline $\mathrm{Na}(\mathrm{mEq} / \mathrm{L})$ & $138(137-141)$ & Recognition threshold for & $1.8(1.0-1.8)$ \\
\hline $\mathrm{K}(\mathrm{mEq} / \mathrm{L})$ & $4.1(3.7-4.6)$ & salty taste $\left(\mathrm{mg} / \mathrm{cm}^{2}\right)$ & \\
\hline
\end{tabular}




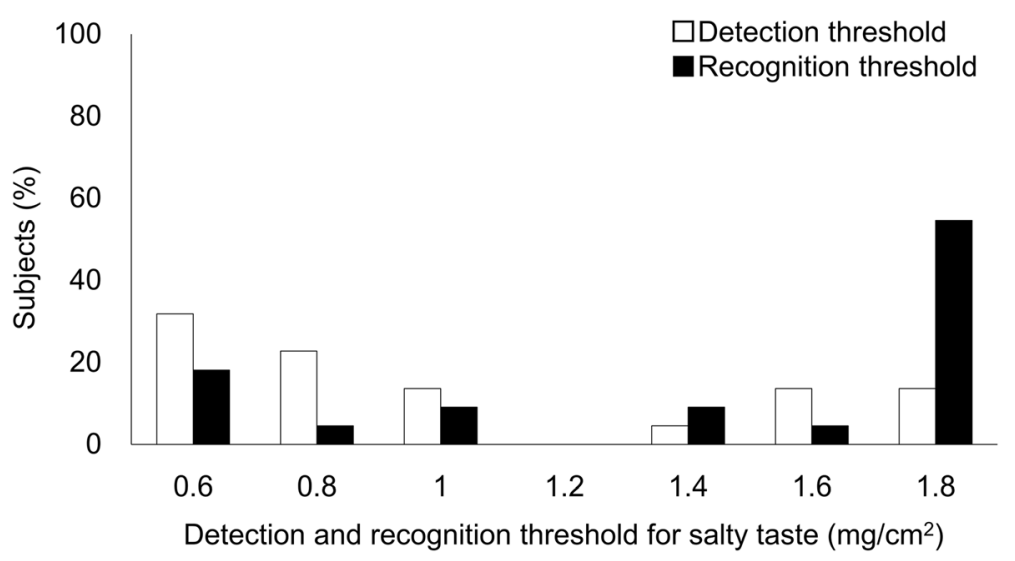

Fig. 1 Distribution of detection and recognition threshold for salty taste in PD patients. Of the PD patients, 68\% presented with a detection threshold above $0.8 \mathrm{mg} / \mathrm{cm}^{2}$, and $14 \%$ could not detect salty taste, even at the highest concentration level $\left(1.6 \mathrm{mg} / \mathrm{cm}^{2}\right)$. Eighty-two percent of the PD patients presented with a recognition threshold above $1.0 \mathrm{mg} / \mathrm{cm}^{2}$, and $55 \%$ could not recognize salty taste, even at the highest concentration level. The normal range of detection threshold is $\leqq 0.6 \mathrm{mg} / \mathrm{cm}^{2}$ and that of recognition threshold is $\leqq 0.8 \mathrm{mg} / \mathrm{cm}^{2}$

\section{The exploratory mining for the discriminative model of the taste disorder}

The discriminative model of the high detection and recognition thresholds was mined via C5.0 decision tree. The candidates of explanatory variables were selected via criteria of $p$ value $<0.05$, in the hypothesis testing of which results are shown in Table 2. The results were shown as decision trees (Figs. 2 and 3); it shows that either having with high serum $\mathrm{P}(>5 \mathrm{mg} / \mathrm{dL})$ or long duration of PD (> 30 months) was the discriminative factor of high detection threshold (Fig. 2), whereas either having with low renal $\mathrm{Kt} / \mathrm{V}(\leq 0.88)$ or long duration of PD ( $>28$ months) was the discriminative factor of the high recognition threshold (Fig. 3).

\section{Discussion}

In this study, we investigated the distribution of the gustatory threshold for salty taste, using the salt-impregnated test strip Salsave, and then analyzed the factors relevant to salty taste disorder in PD patients. Our results showed that the gustatory threshold for salty taste was increased in these patients. In addition, we found that either having with high serum $\mathrm{P}$ or long duration of $\mathrm{PD}$, and with low renal $\mathrm{Kt} / \mathrm{V}$ or long duration of $\mathrm{PD}$ were discriminative factors of high detection threshold and high recognition threshold, respectively, via the data mining following the univariate analysis.

Previous reports found that the prevalence of taste disorder among CKD and ESRD patients ranged from 31 to 95\% [26, 27], whereas among the general population aged 40 years old or older, only $26 \%$ of adults had salty taste disorder [24]. Similarly, our results showed that $82 \%$ of PD patients had high recognition threshold for salty taste. Surprisingly, most PD patients in our study were not aware of their taste disorder before the taste assessment. These results suggested that PD patients have a high risk of salty taste disorder.

The causes of taste disorder in CKD and ESRD patients are not fully investigated; however, many factors such as uremic toxins, zinc deficiency, and high salt intake itself were reported [15-17]. Uremic toxins were reported to cause reduction in taste activity via neuropathy [28]. In CKD patients, uremic toxins in the saliva were increased [20, 29], and elevated salivary uremic toxins may play a part in taste disorder. In the present study, the univariate analysis showed that high serum uremic toxins $\left(\mathrm{Cr}\right.$ and $\beta_{2}$ microglobulin) were associated with high recognition threshold, but urea was not associated with it. Furthermore, the partition analysis via C5.0 algorithm showed that either having with low renal Kt/V or long duration of PD (> 28 months) was the discriminative factor of high recognition threshold. Renal $\mathrm{Kt} / \mathrm{V}$ is the marker of small molecular weight uremic toxin removal and is assessed by urea removal and urinary volume. However, the univariate analysis showed that both urea and urinary volume were not associated with recognition threshold. Thus, small molecular weight uremic toxin (other than urea) may affect salty taste activity in PD patients. On the other hand, from univariate analysis, middle or large molecular weight uremic toxins (including $\beta_{2}$ microglobulin) may also have an effect.

Unlike high recognition threshold, the result of mining via C5.0 showed that subjects with high detection threshold were discriminated by having with high serum $\mathrm{P}$ or long duration of PD (>30 months). In CKD and ESRD patients, a limited number of studies have reported the relationship between serum $\mathrm{P}$ and taste disorder, and a previous study showed that 
Table 2 Comparison of clinical characteristics between low and high gustatory threshold for salty taste

\begin{tabular}{|c|c|c|c|c|c|c|}
\hline & \multicolumn{3}{|l|}{ Detection threshold } & \multicolumn{3}{|l|}{ Recognition threshold } \\
\hline & $\begin{array}{l}\text { Normal }\left(\leqq 0.6 \mathrm{mg} / \mathrm{cm}^{2}\right) \\
n=7\end{array}$ & $\begin{array}{l}\text { High }\left(\geqq 0.8 \mathrm{mg} / \mathrm{cm}^{2}\right) \\
n=15\end{array}$ & $P$ value & $\begin{array}{l}\text { Normal }\left(\leqq 0.8 \mathrm{mg} / \mathrm{cm}^{2}\right) \\
n=5\end{array}$ & $\begin{array}{l}\text { High }\left(\geqq 1.0 \mathrm{mg} / \mathrm{cm}^{2}\right) \\
n=17\end{array}$ & $P$ value \\
\hline Age (years) & $78(61-87)$ & $61(52-68)$ & 0.029 & $78(49-88)$ & $63(54-73)$ & 0.327 \\
\hline Male:female & $5: 2$ & $5: 10$ & 0.172 & $3: 2$ & $7: 10$ & 0.624 \\
\hline Duration of PD (months) & $7(6-24)$ & $54(16-66)$ & 0.041 & $6(4-21)$ & $39(12-65)$ & 0.046 \\
\hline \multicolumn{7}{|l|}{ Comorbidity (\%) } \\
\hline Hypertension & 83.3 & 86.7 & $>0.99$ & 75.0 & 88.2 & 0.489 \\
\hline Diabetes mellitus & 16.7 & 26.7 & $>0.99$ & 50.0 & 17.7 & 0.228 \\
\hline Cardiovascular diseases & 33.3 & 13.3 & 0.544 & 50.0 & 11.8 & 0.148 \\
\hline Body weight (kg) & $64(46.1-69.1)$ & $59(51.5-63)$ & 0.647 & $55(44-69)$ & $60(54-64)$ & 0.611 \\
\hline Systolic BP (mmHg) & $133(121-145)$ & $133(123-142)$ & 0.916 & $133(118-145)$ & $132(122-144)$ & 0.845 \\
\hline Diastolic BP (mmHg) & $70(62-87)$ & $71(57-84)$ & 0.778 & $65(56-87)$ & $71(58-85)$ & 0.845 \\
\hline Effluent volume (mL/day) & $300(150-416)$ & $274(170-746)$ & 0.631 & $342(150-416)$ & $274(170-746)$ & 0.695 \\
\hline Urinary volume (mL/day) & $1250(1000-1500)$ & $1000(750-1500)$ & 0.374 & $1500(1175-1650)$ & $1000(815-1400)$ & 0.123 \\
\hline $\mathrm{Hb}(\mathrm{g} / \mathrm{dL})$ & $11.1(10.5-12.1)$ & $10.7(9.7-11.7)$ & 0.597 & $11.1(10.7-12.3)$ & $10.7(9.7-11.6)$ & 0.158 \\
\hline $\mathrm{TP}(\mathrm{g} / \mathrm{dL})$ & $6.8(6.7-6.8)$ & $6.2(5.9-7)$ & 0.119 & $6.8(6.5-7.2)$ & $6.4(5.9-6.9)$ & 0.146 \\
\hline Alb $(g / d L)$ & $3.4(3-3.7)$ & $3.4(3.1-3.6)$ & 0.859 & $3.2(3.0-3.6)$ & $3.4(3.2-3.7)$ & 0.325 \\
\hline $\mathrm{Na}(\mathrm{mEq} / \mathrm{L})$ & $138(137-140)$ & $138(136-143)$ & 0.972 & $138(137-141)$ & $138(137-142)$ & 0.752 \\
\hline $\mathrm{K}(\mathrm{mEq} / \mathrm{L})$ & $4.6(4.1-5.1)$ & $4.0(3.4-4.5)$ & 0.052 & $4.9(4.1-5.3)$ & $4.0(3.5-4.6)$ & 0.065 \\
\hline $\mathrm{Cl}(\mathrm{mEq} / \mathrm{L})$ & $105(103-106)$ & $103(98-106)$ & 0.455 & 105 (100-106) & 103 (99-106) & 0.901 \\
\hline Corrected Ca (mg/dL) & $9.9(8.6-10.1)$ & $9.5(9.3-10.2)$ & 0.479 & $9.9(9.0-10.1)$ & $9.5(9.1-10.2)$ & 0.875 \\
\hline$P(m g / d L)$ & $3.9(3.4-4.2)$ & $5.2(4.3-5.7)$ & 0.009 & $3.9(3.4-4.3)$ & $5.1(4.1-5.7)$ & 0.029 \\
\hline $\mathrm{Zn}(\mathrm{mg} / \mathrm{dL})$ & $68(58-84)$ & $60(54-77)$ & 0.467 & $82(56-88)$ & $61(54-76)$ & 0.201 \\
\hline Intact-PTH (pg/mL) & $163(33-260)$ & 137 (69-196) & 0.597 & $49(37-211)$ & $140(76-236)$ & 0.147 \\
\hline BUN (mg/dL) & $54(49-60)$ & $55(46-61)$ & 0.944 & $49(44-68)$ & $55(48-61)$ & 0.530 \\
\hline $\mathrm{Cr}(\mathrm{mg} / \mathrm{dL})$ & $6.3(4.2-7.6)$ & $8.5(6.2-11.9)$ & 0.084 & $6.1(4.1-6.8)$ & $8.4(6.8-11.8)$ & 0.017 \\
\hline UA (mg/dL) & $7.2(5.6-7.9)$ & $6.2(5.4-6.9)$ & 0.158 & $5.6(4.9-8.4)$ & $6.5(5.4-7.0)$ & 0.814 \\
\hline$\beta_{2}$ microglobulin (mg/L) & $12(10-17)$ & $19(12-23)$ & 0.061 & $12(10-13)$ & $19(15-23)$ & 0.007 \\
\hline Ferritin (ng/mL) & $151(66-280)$ & 168 (99-307) & 0.647 & $95(59-236)$ & $168(105-299)$ & 0.290 \\
\hline TSAT (\%) & $28(22-33)$ & $39(28-53)$ & 0.045 & $28(22-34)$ & $35(27-52)$ & 0.108 \\
\hline $\mathrm{HCO}_{3}{ }^{-}(\mathrm{mmol} / \mathrm{L})$ & $23(23-28)$ & $24(23-28)$ & 0.526 & $26(22-29)$ & $24(23-27)$ & 0.505 \\
\hline CRP $(\mathrm{mg} / \mathrm{dL})$ & $0.21(0.09-0.28)$ & $0.10(0.02-1.20)$ & 0.606 & $0.16(0.12-0.49)$ & $0.14(0.02-0.99)$ & 0.694 \\
\hline Urinary protein $(\mathrm{g} / \mathrm{g} \mathrm{Cr}$ ) & $1.1(0.3-3.5)$ & $2.1(0.7-3.7)$ & 0.436 & $2.3(0.5-3.8)$ & $1.1(0.7-3.6)$ & 0.788 \\
\hline CTR (\%) & $50(48-58)$ & $50(47-59)$ & 0.859 & $48(48-58)$ & $50(48-59)$ & 0.636 \\
\hline Total Kt/N & $1.81(1.63-2.26)$ & $2.00(1.81-2.47)$ & 0.259 & $2.26(1.71-2.66)$ & $1.96(1.80-2.24)$ & 0.666 \\
\hline Peritoneal Kt/N & $0.98(0.54-1.17)$ & $1.31(0.90-1.87)$ & 0.053 & $0.59(0.47-1.08)$ & $1.31(0.94-1.87)$ & 0.015 \\
\hline Renal Kt/N & $1.09(0.55-1.25)$ & $0.85(0.37-1.31)$ & 0.597 & $1.25(1.16-1.87)$ & $0.74(0.30-0.99)$ & 0.017 \\
\hline Salt excretion (g/day) & $9.5(4.7-11.6)$ & $7.9(6.8-10.7)$ & 0.967 & $11.0(4.5-11.4)$ & $7.7(6.3-10.4)$ & 0.485 \\
\hline
\end{tabular}

Data are shown as $n$ (\%) or median (interquartile range)

Fisher's exact test was used to compare nominal variables, and Wilcoxon rank-sum test was used for continuous variables

$A l b$ albumin, BP blood pressure, BUN blood urea nitrogen, $C a$ calcium, $C l$ chloride, $C r$ creatinine, CRP C-reactive protein, CTR cardiothoracic ratio, $H b$ hemoglobin, $K$ potassium, Na sodium, $P$ phosphorus, $P D$ peritoneal dialysis, $P T H$ parathyroid hormone, TP total protein, TSAT transferrin saturation, UA uric acid, $Z n$ zinc

serum $\mathrm{P}$ was not related with taste disorder in HD patients [30]. In CKD and ESRD patients, serum $P$ level was affected by various factors including diet, drugs, and endocrine hormone; therefore, these factors might have affected the detection threshold in PD patients. 


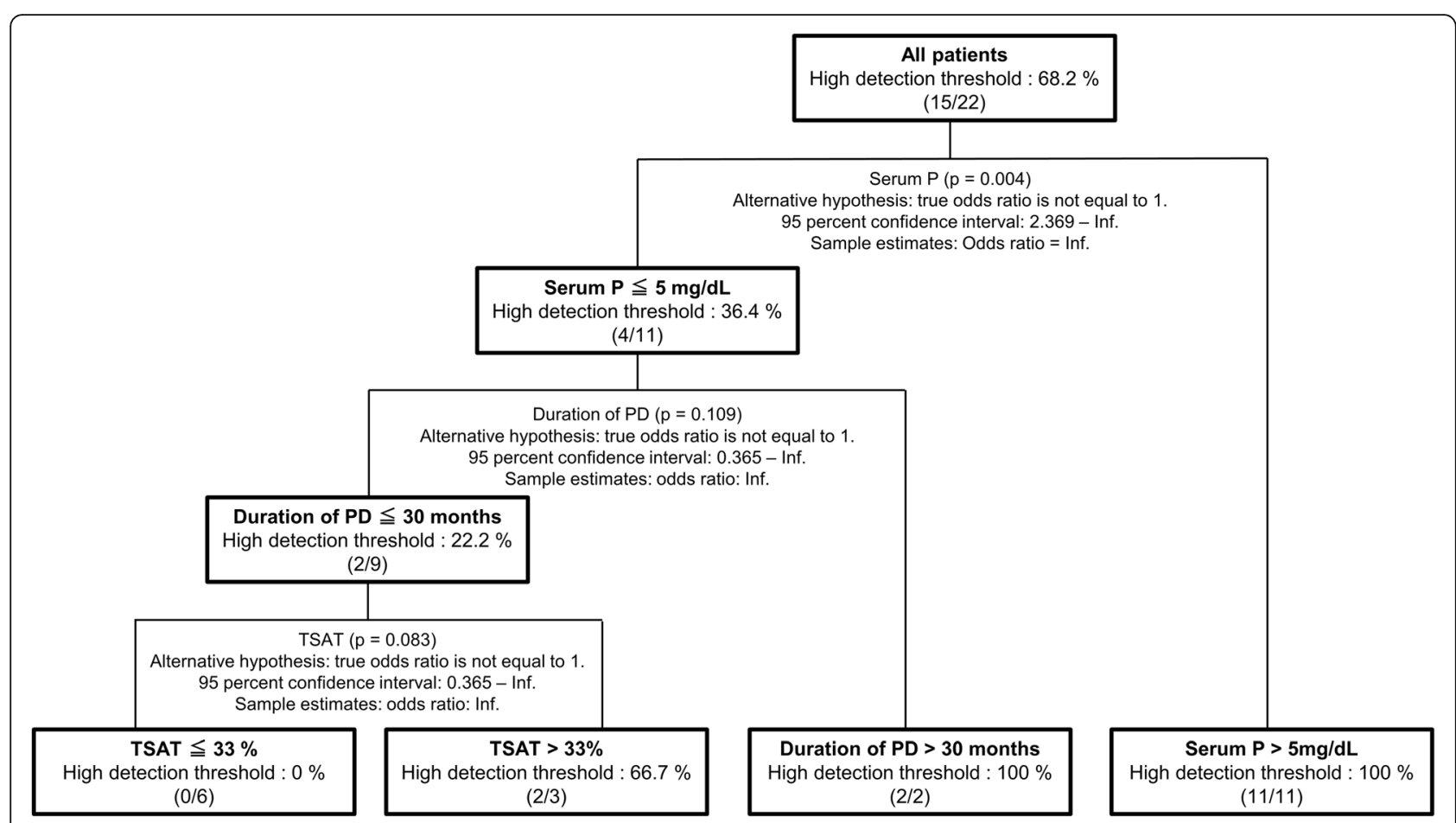

Fig. 2 The decision tree for high detection threshold for salty taste. Inf = infinity; $\mathrm{p}=\mathrm{p}$ value from the Fisher's exact test to assess the association between detection threshold and serum P, duration of PD, or TSAT

In the present study, factors that affect recognition and detection thresholds varied. A previous study also showed that the factors that affect recognition and detection thresholds are different. However, as with uremic toxin, serum $P$ is efficiently removed by the residual kidney [31]. Furthermore, duration of PD was related with both recognition and detection threshold. Residual renal function declines over time in PD patients [32]. Thus, residual renal function might affect both detection and recognition threshold for salty taste. On the contrary, salt intake is associated with an undetectable recognition threshold in CKD patients [19]; thus, we think that recognition threshold is also more important than detection threshold in PD patients.

Although zinc deficiency is known as the common cause of taste disorder in renal disease patients [15, 27], there was no relationship between serum zinc and salty taste threshold in our results. Although one previous study showed that zinc supplement did not improve taste activity in HD patients [33], zinc deficiency may not contribute to taste disorder as much as reported previously. In addition, high salt intake itself was known to be associated with salty taste disorder [11]. In this study, we evaluated the amount of salt excretion when patients took low-salt diet during hospitalization. Thus, the amount of salt excretion might be affected by hospital diet, and we could not find the association between the amount of salt excretion and recognition threshold for salty taste.

In this study, we measured the gustatory threshold for salty taste by a salt-impregnated taste strip Salsave. Many methods for taste assessment, such as wholemouth method, micropipette method, and electrogustometry, are available, but most of them are complex tests that are not appropriate for routine clinical screening [19]. On the contrary, the Salsave examination can be easily performed in the clinical setting and does not require special training. Since the gustatory threshold assessed by Salsave is semi-quantitative and subjective, there is a concern about the accuracy of the taste threshold. However, the magnitude of the recognition threshold for salty taste measured by Salsave was reported to correlate with the results of other taste tests including electrogustometry [23]. Therefore, we consider that the gustatory threshold in this study reflects the true taste activity.

This study has several limitations including those mentioned above. First, we did not assess oral conditions that affected taste activity such as salivary composition, number of taste buds, and dry mouth. Thus, we could not exclude the possibility that oral conditions affected the taste activity in this study. Second, this study has a very small sample size, and we could not exclude the existence of unrecognized confounding 


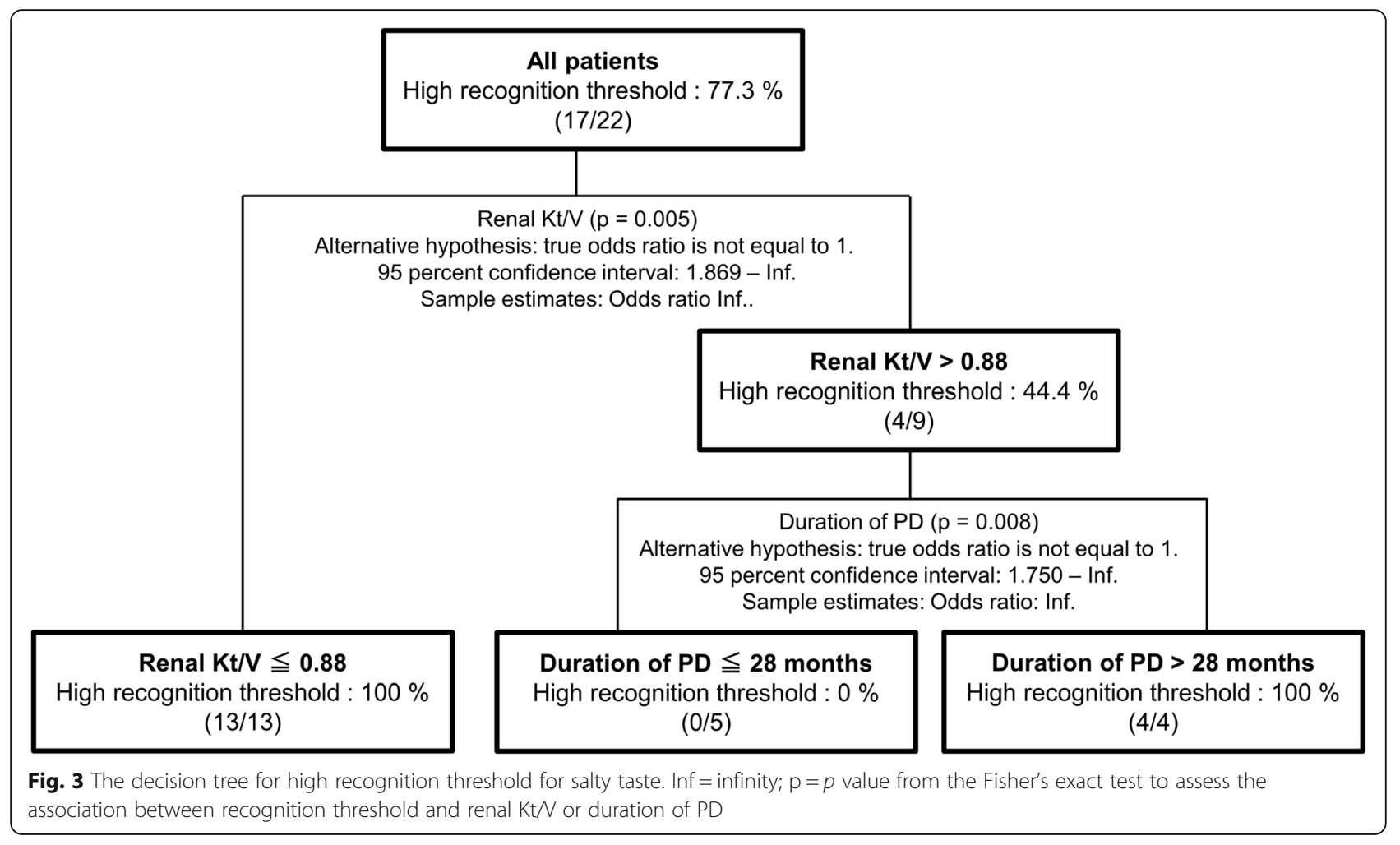

factors that affect the observed associations. Third, this was a retrospective cross-sectional study; hence, causal relationships between salty taste recognition threshold and residual renal function cannot be conclusive. A large and prospective study is needed to investigate whether residual renal function is the cause of salty taste disorder.

\section{Conclusion}

This study showed that the gustatory threshold for salty taste was increased in PD patients. High detection threshold was related to high serum $\mathrm{P}$, and high recognition threshold was related to low renal Kt/V. Based on these findings, it is important to assess the gustatory threshold for salty taste in PD patients, particularly in those with high serum $\mathrm{P}$ and low renal $\mathrm{Kt} / \mathrm{V}$. In addition, the assessment of the gustatory threshold for salty taste might help implement salt-restricted diet in PD patients.

\section{Abbreviations}

Alb: Albumin; BUN: Blood urea nitrogen; CKD: Chronic kidney disease;

ESRD: End-stage renal disease; HD: Hemodialysis; P: Phosphorus;

PD: Peritoneal dialysis; TSAT: Transferrin saturation

\section{Authors' contributions}

$\mathrm{KT}$ contributed to the study design, date acquisition, analysis of data, interpretation of data, and drafting of the manuscript. YO contributed to the study design, interpretation of data, and the critical revision of the manuscript. SM contributed to the analysis, interpretation of data, and the critical revision of the manuscript. MT and SO contributed to the study design. TU contributed to date acquisition. HM contributed to the interpretation of data. TN contributed to the study design, interpretation of data, critical revision of the manuscript, and study supervision. All authors read and approved the final manuscript.

Funding

The authors did not receive any funding for this study.

\section{Availability of data and materials}

The datasets used and/or analyzed during the current study are available from the corresponding author on reasonable request.

\section{Ethics approval and consent to participate}

This study was conducted in accordance with the Declaration of Helsinki and the Ethical Guidelines for Medical and Health Research Involving Human Subjects. The ethics review board of the university hospital approved the study protocol (approval number: 18031904).

\section{Consent for publication}

Not applicable.

Competing interests

The authors declare that they have no competing interests.

\section{Author details}

${ }^{1}$ Department of Nephrology, Nagasaki University Graduate School of Biomedical Sciences, 1-7-1 Sakamoto, Nagasaki 852-8501, Japan. ${ }^{2}$ Medical Educational Development Center, Nagasaki University Hospital, 1-7-1 Sakamoto, Nagasaki 852-8501, Japan. ${ }^{3}$ Innovation Platform \& Office for Precision Medicine, Nagasaki University Graduate School of Biomedical Sciences, 1-7-1 Sakamoto, Nagasaki 852-8501, Japan. ${ }^{4}$ Department of 
Respiratory Medicine, Nagasaki University Graduate School of Biomedical Sciences, 1-7-1 Sakamoto, Nagasaki 852-8501, Japan.

Received: 21 November 2018 Accepted: 23 August 2019

Published online: 05 September 2019

\section{References}

1. Strazzullo P, D'Elia L, Kandala N-B, Cappuccio FP. Salt intake, stroke, and cardiovascular disease: meta-analysis of prospective studies. BMJ. 2009;339:b4567.

2. Yang Q, Liu T, Kuklina EV, Flanders WD, Hong Y, Gillespie C, et al. Sodium and potassium intake and mortality among US adults: prospective data from the Third National Health and Nutrition Examination Survey. Arch Intern Med. 2011;171:1183-91.

3. Koomans HA, Roos JC, Boer P, Geyskes GG, Mees EJ. Salt sensitivity of blood pressure in chronic renal failure. Evidence for renal control of body fluid distribution in man. Hypertension. 1982:4:190-7.

4. Locatelli F, Covic A, Chazot C, Leunissen K, Luño J, Yaqoob M. Hypertension and cardiovascular risk assessment in dialysis patients. Nephrol Dial Transplant. 2004;19:1058-68.

5. Weir MR, Fink JC. Salt intake and progression of chronic kidney disease: an overlooked modifiable exposure? A commentary. Am J Kidney Dis. 2005:45:176-88.

6. Inker LA, Astor BC, Fox CH, Isakova T, Lash JP, Peralta CA, et al. KDOQI US commentary on the $2012 \mathrm{KDIGO}$ clinical practice guideline for the evaluation and management of CKD. Am J Kidney Dis. 2014; 63:713-35.

7. National Kidney Foundation. KDOQI clinical practice guideline for hemodialysis adequacy: 2015 update. Am J Kidney Dis. 2015;66:884-930

8. Wang AYM, Brimble KS, Brunier G, Holt SG, Jha V, Johnson DW, et al. ISPD cardiovascular and metabolic guidelines in adult peritoneal dialysis patients part I - assessment and management of various cardiovascular risk factors. Perit Dial Int. 2015;35:379-87.

9. Welch JL, Bennett SJ, Delp RL, Agarwal R. Benefits of and barriers to dietary sodium adherence. West J Nurs Res. 2006;28:162-80; discussion 181-9.

10. McMahon EJ, Campbell KL, Mudge DW, Bauer JD. Achieving salt restriction in chronic kidney disease. Int J Nephrol. 2012. https://doi. org/10.1155/2012/720429.

11. Piovesana PDM, Sampaio KDL, Gallani MCBJ. Association between taste sensitivity and self-reported and objective measures of salt intake among hypertensive and normotensive individuals. ISRN Nutr. 2013. https://doi.org/10.5402/2013/301213.

12. Mcmahon EJ, Campbell KL, Bauer JD. Taste perception in kidney disease and relationship to dietary sodium intake. Appetite. 2014;83: 236-41.

13. Fornari AJ, Avram MM. Altered taste perception in uremia. Trans Am Soc Artif Intern Organs. 1978;24:385-8.

14. Fernström A, Hylander B, Rössner S. Taste acuity in patients with chronic renal failure. Clin Nephrol. 1996;45:169-74.

15. Mahajan SK, Prasad AS, Lambujon J, Abbasi AA, Briggs WA, McDonald FD. Improvement of uremic hypogeusia by zinc: a double-blind study. Am J Clin Nutr. 1980;33:1517-21.

16. Burge JC, Park HS, Whitlock CP, Schemmel RA. Taste acuity in patients undergoing long-term hemodialysis. Kidney Int. 1979:15:49-53.

17. Huggins RL, Di Nicolantonio R, Morgan TO. Preferred salt levels and salt taste acuity in human subjects after ingestion of untasted salt. Appetite. 1992;18:111-9.

18. Beauchamp GK, Bertino M, Burke D, Engelman K. Experimental sodium depletion and salt taste in normal human volunteers. Am J Clin Nutr. 1990;51:881-9.

19. Kusaba T, Mori Y, Masami O, Hiroko N, Adachi T, Sugishita C, et al, Sodium restriction improves the gustatory threshold for salty taste in patients with chronic kidney disease. Kidney Int. 2009;76:638-43.

20. Manley KJ, Haryono RY, Keast RSJ. Taste changes and saliva composition in chronic kidney disease. Ren Soc Australas J. 2012;8:56-60.

21. Astbäck J, Fernström A, Hylander B, Arvidson K, Johansson O. Taste buds and neuronal markers in patients with chronic renal failure. Perit Dial Int. 1999;19(Suppl 2):315-23.

22. Middleton RA, Allman-Farinelli MA. Taste sensitivity is altered in patients with chronic renal failure receiving continuous ambulatory peritoneal dialysis. J Nutr. 1999;129:122-5.
23. Nishimoto K, Hirota R, Egawa M, Furuta S. Clinical evaluation of taste dysfunction using a salt-impregnated taste strip. ORL J Otorhinolaryngol Relat Spec. 1996;58:258-61.

24. Michikawa T, Nishiwaki Y, Okamura T, Asakura K, Nakano M, Takebayashi T. The taste of salt measured by a simple test and blood pressure in Japanese women and men. Hypertens Res. 2009;32:399-403.

25. Nishimoto K, Ohhori J, Shimomugi T, Kurono Y. Reproducibility of taste examination with Salsave: control study for healthy volunteers. Japan Society of Stomato-pharyngology. 2005;17:309-15. (In Japanese).

26. Bots CP, Poorterman JHG, Brand HS, Kalsbeek H, Van Amerongen BM, Veerman $\mathrm{ECl}$, et al. The oral health status of dentate patients with chronic renal failure undergoing dialysis therapy. Oral Dis. 2006;12: $176-80$.

27. Atkin-Thor E, Goddard BW, O'Nion J, Stephen RL, Kolff WJ. Hypogeusia and zinc depletion in chronic dialysis patients. Am J Clin Nutr. 1978; 31:1948-51

28. Ciechanover M, Peresecenschi G, Aviram A, Steiner JE. Malrecognition of taste in uremia. Nephron. 1980;26:20-2.

29. Michelis R, Sela S, Ben-Zvi I, Nagler RM. Salivary beta2-microglobulin analysis in chronic kidney disease and hemodialyzed patients. Blood Purif. 2007;25:505-9.

30. Lynch KE, Lynch R, Curhan GC, Brunelli SM. Altered taste perception and nutritional status among hemodialysis patients. J Ren Nutr. 2013; 23:288-295.e1.

31. Bammens B, Evenepoel P, Verbeke $K$, Vanrenterghem Y. Removal of middle molecules and protein-bound solutes by peritoneal dialysis and relation with uremic symptoms. Kidney Int. 2003;64:2238-43.

32. Michels WM, Verduijn M, Grootendorst DC, et al. Decline in residual renal function in automated compared with continuous ambulatory peritoneal dialysis. Clin J Am Soc Nephrol. 2011;6:537-42.

33. Matson A, Wright M, Oliver A, Woodrow G, King N, Dye L, et al. Zinc supplementation at conventional doses does not improve the disturbance of taste perception in hemodialysis patients. J Ren Nutr. 2003:13:224-8.

\section{Publisher's Note}

Springer Nature remains neutral with regard to jurisdictional claims in published maps and institutional affiliations.

Ready to submit your research? Choose BMC and benefit from

- fast, convenient online submission

- thorough peer review by experienced researchers in your field

- rapid publication on acceptance

- support for research data, including large and complex data types

- gold Open Access which fosters wider collaboration and increased citations

- maximum visibility for your research: over $100 \mathrm{M}$ website views per year

At BMC, research is always in progress.

Learn more biomedcentral.com/submissions 